\title{
Morphology Behavior of Copper Films Deposited after Wet Surface Treatment on Polished Alumina
}

\author{
Alexander Flacker, ${ }^{\circledR * a}{ }^{*}$ Gabriela C. Gomes, ${ }^{a}$ Michele $O$. Silva ${ }^{a}$ and Ricardo C. Teixeira ${ }^{\oplus a}$ \\ ${ }^{a}$ Centro de Tecnologia da Informação Renato Archer (CTI), Rodovia D. Pedro 1 (SP-065), km 143.6, \\ 13069-901 Campinas-SP, Brazil
}

\begin{abstract}
In this paper, a pre-treatment process for electroless copper $(\mathrm{Cu})$ deposition on the polished alumina $\left(\mathrm{Al}_{2} \mathrm{O}_{3}\right) 99.9 \%$ and the behavior of $\mathrm{Cu}$ plating by electroless process after $\mathrm{Al}_{2} \mathrm{O}_{3}$ surface treatment were explored. Our work was carried out by changing the roughness of $\mathrm{Al}_{2} \mathrm{O}_{3}$ through micro-etching (coarsening), nucleation its surface by a two-step method (sensitization and activation) and electroless $\mathrm{Cu}$ plating deposited using non-commercial solution having formaldehyde as reducer, alkaline $\mathrm{pH}$ and operating temperature of $30^{\circ} \mathrm{C}$. Contact angle system (CA), scanning electron microscopy (SEM), energy dispersive spectroscopy (EDS), mechanical profilometer (DekTak XT) atomic force microscopy (AFM) and analysis by Gwyddion v2.27 software were used to evaluate the wet treatment and the morphology of the electroless deposition (ED) of $\mathrm{Cu}$ on the $\mathrm{Al}_{2} \mathrm{O}_{3}$ surface. The results show that the surface treatment of purity polished $\mathrm{Al}_{2} \mathrm{O}_{3}$ with $0.1 \%$ of vitreous materials present into the substrate surface, presents a high performance in $\mathrm{ED}$ film at low temperature $\left(30^{\circ} \mathrm{C}\right)$, during the $\mathrm{Cu}$ deposition, obtaining more compact and uniform film, with small grain size, uniform thickness, and a high purity $\mathrm{Cu}$ metallic deposit.
\end{abstract}

Keywords: electroless copper deposition, wet surface treatment, surface morphology, alumina, coarsening, nucleation

\section{Introduction}

Electroless deposition (ED) of metals and alloys on non-metallic materials such as ceramics, carbon, plastics, polymers, semiconductors and dielectrics are increasing for a wide range of commercial applications..$^{1-8}$ The process is particularly important in the printed circuit industry. ${ }^{9}$ For example, polished alumina $\left(\mathrm{Al}_{2} \mathrm{O}_{3}\right)$ has been used as an interconnect substrate onto which a conductive metal layer, such as gold or copper, can be applied ${ }^{8}$ by ED, since it is a low-cost process compared to other methods, such as plasma spraying, physical vapor deposition (PVD) chemical vapor deposition (CVD) or electrodeposition. ${ }^{10} \mathrm{ED}$ (autocatalytic) plating involves the presence of a chemical reducing agent in solution to reduce metallic ions to the metal state. The name electroless is somewhat misleading, however. There are no external electrodes present, but there is electric current (charge transfer) involved. Instead of an anode, salt supplied the metal. The process takes place only on catalytic surfaces rather than throughout the solution. If

*e-mail: alexflacker@gmail.com

Editor handled this article: Rodrigo A. A. Muñoz (Associate) the process is not properly controlled, the reduction can take place throughout the solution, possibly on particles of dust or of catalytic metals, with undesirable results like the decomposition of the solution. Autocatalytic plating is defined as the deposition of a metallic coating by a controlled chemical reduction that is catalyzed by the metal or alloy being deposited. Such plating has been used to yield deposits of nickel (Ni), nickel phosphorus $(\mathrm{Ni}-\mathrm{P})$, copper $(\mathrm{Cu})$, cobalt $(\mathrm{Co})$, palladium $(\mathrm{Pd})$, silver $(\mathrm{Ag})$ and gold $(\mathrm{Au})$. For $\mathrm{Cu}$ electroless deposition, chemical reducing agents have included formaldehyde as the most important (the one originally used by the inventors for $\mathrm{Ni}$ and $\mathrm{Cu}$ deposition and still the most important and widely investigated).

Among the various engineering ceramics, $\mathrm{Al}_{2} \mathrm{O}_{3}$ is one of the most widely used in the engineering materials due to is good mechanical properties, high hardness and low density. ${ }^{11}$ However in some situations, the toughness, electric conductivity and the thermoconductivity of the ceramic need to be enhanced. ${ }^{12}$ Electroless $\mathrm{Cu}$ films exhibit many advantages such as remarkable electric, magnetic and heat conducting properties. ${ }^{13}$ However, $\mathrm{Al}_{2} \mathrm{O}_{3}$ ceramic shows no affinity to a metal plating and simple physical 
deposition cannot be effective to complete copper plating on its surface. ${ }^{14}$ To reach the required properties of the $\mathrm{Cu}$ layer, besides the bulk composition and properties of the $\mathrm{Cu}$ materials, the process that occur at the substrate surface before deposition are also important. ${ }^{15}$ The cleanliness, the chemical composition of the surface, coarsening and the nucleation influence the initiation and the subsequent adhesion, both during and after deposition..$^{16,17}$

Coarsening (surface modification) is an important step in the process to obtain a surface with a few nanometers of roughness on a polished alumina. So, it is necessary to carry out a sufficient coarsening to allow the pretreatment process with Sn and Pd deposition. Pre-treatment process of Sn-Pd has been used for decades; however, concerns about the low efficiency and risks of contamination remain unresolved. Many attempts were made to find a single-step catalyzing procedure to replace the two-step method with a more efficient method, such as the Pd-Sn colloidal deposition, noble metal prints, and vacuum deposition methods. Nevertheless, these techniques are either costly or require additional processing steps which reduce the efficiency. ${ }^{8}$

Many aspects of nucleation on the substrate surface have been investigated.$^{18}$ For the nucleation procedure, a one-step and a two-step process have been distinguished. ${ }^{19}$ For the one-step nucleation, samples are immersed in a $\mathrm{SnCl}_{2}-\mathrm{PdCl}_{2}$ colloidal solution. ${ }^{20,21}$ In the two-step procedure, substrates are sensitized by immersion in a $\mathrm{SnCl}_{2}$ containing solution and activated with a $\mathrm{PdCl}_{2}$ solution. ${ }^{10,16,22}$

According to Svendsen et al. ${ }^{23}$ the one-step nucleation procedure is not suitable for alumina substrates. This is confirmed by Honma et al. ${ }^{24,25}$ who reported that with a two-step procedure, the adhesion of $\mathrm{Cu}$ on alumina is stronger than with a one-step procedure, as measured by the direct pull-off technique.

Generally, three different goals can be distinguished for the pretreatments: first, adsorbed organic contaminations and particles are removed in a cleaning step. Second, by coarsening the substrate, the surface roughness is increased and possible sites for mechanical interlocking are created to improve adhesion. Third, by the nucleation procedure the surface of the substrate was turned catalytic by using the two-step procedure ( $\mathrm{Sn}$ and $\mathrm{Pd}$ ) followed by immersion in an accelerator ${ }^{26-28}$ for ED deposition.

Copper is a less noble metal, but many studies ${ }^{29,30}$ have considered it as a good candidate for the design of new catalysts, especially because of its very remarkable electric conductivity, good stability and low-cost.

Electroless copper deposition is a promising route to realize copper-based catalysts due to is relatively low-cost, simplicity, low processing temperature, good adherence and the high physicochemical properties of the deposit. ${ }^{31}$
This work reports the effect of the treatment performed on the polycrystalline alumina surface by comparing the contact angle (CA) before and after coarsening. The morphology and roughness of the electroless $\mathrm{Cu}$ deposition system performed on the alumina coarsened was studied combining atomic force microscopy (AFM), mechanical profilometer (DekTak XT) and scanning electron microscope (SEM). The aim of this study has been, on the one hand, to expand the current knowledge about the process of obtaining a catalytic surface to enable the electroless deposition of $\mathrm{Cu}$ on alumina, and on the other, to carry out characterization that can identify the quality of the deposited $\mathrm{Cu}$.

To the best of our knowledge, there have been no previous reports of $\mathrm{ED}$ of $\mathrm{Cu}$ on polished $\mathrm{Al}_{2} \mathrm{O}_{3} 99.9 \%$ using wet treatment. This technique, after micro corrosion, allows nuclear $(\mathrm{Sn}+\mathrm{Pd})$ on $0.1 \%$ of vitreous material incorporated on the substrate surface and practically does not change the roughness of the treated surface. Considering the sub micrometric dimensions of the $\mathrm{Cu}$ grains, it favors the application of the film in high-density circuits with interconnection paths with a few microns lines.

\section{Experimental}

Ninety nine point nine percent ADS polished alumina ceramic (CoorsTek, Golden, USA), with dimensions $25.4 \times 25.4 \times 0.6 \mathrm{~mm}$ was used as substrate due to its excellent mechanical properties, low roughness $(<1 \mu \mathrm{m})$, excellent corrosion resistance and uniform density $\left(3.87 \mathrm{~g} \mathrm{cc}^{-1}\right){ }^{32}$

\section{Cleaning}

Under magnetic agitation, samples were cleaned with $\mathrm{H}_{2} \mathrm{SO}_{4}$ (95-97\% PA, Merck, Darmstadt, Germany) and nitric acid (62-70\% ACS, JT Baker, New Jersey, USA) solution 19:1 (vol\%), during $5 \mathrm{~min}$ at $60{ }^{\circ} \mathrm{C}$ to remove organic contamination and particles remaining from the fabrication polishing, followed by rinsed in circulation de-ionized (DI) water for $2 \mathrm{~min}$ and sonicated for $2 \mathrm{~min}$.

\section{Coarsening}

Particles on the alumina surface are activated by coarsening the micron sized $\mathrm{Al}_{2} \mathrm{O}_{3}$ particles into $\mathrm{NaOH}$ (PA-ACS, Dinâmica, Indaiatuba, Brazil) solution then, slowly placed on a heating hot plate and remaining for 10 min at $400{ }^{\circ} \mathrm{C}$. In the sequence, it was immersed in $\mathrm{H}_{2} \mathrm{SO}_{4}$ solution at room temperature and washed with DI water. ${ }^{33}$ 
Coarsening not only improves the mechanical bonding of the metallic seeds with the substrate, but also improves the wetting of the seeding solution. ${ }^{34}$

\section{Nucleation}

Several methods for surface activation are reported in the literature, ${ }^{10,35-37}$ all based on solutions containing $\mathrm{Sn}^{2+}$ and $\mathrm{Pd}^{2+}$ species. The first bath is referred as the sensitizer stannous chloride solution $\left(\mathrm{SnCl}_{2}\right)$, while the second bath is referred as the activator palladium solution $\left(\mathrm{PdCl}_{2}\right)$. The result of the pretreatment sequence is the formation of finely divided palladium nuclei. The formation of the palladium nuclei is believed to be due to a redox reaction taking place between the adsorbed or absorbed stannous ions on the surface (formation of mechanical bonding) and the palladium ions in the activation solution. ${ }^{36}$ The sensitization and activation step can be described by equation 1 , as reported in the literature. . $3,36-40^{-}$

$\mathrm{Sn}^{2+}+\mathrm{Pd}^{2+} \rightarrow \mathrm{Sn}^{4+}+\mathrm{Pd}^{0}$

The composition of the sensitization and activation solutions is given in Table 1.

The process of nucleation occurs in only one face (polished). The other face (unpolished) of the pretreated alumina was wrapped after coarsening with insulating tape (3M, Sumaré, Brazil) to prevent sensitization and activation. The alumina substrate was seeded with palladium by being dipped successively in acid $\mathrm{SnCl}_{2}$ solution followed by acid $\mathrm{PdCl}_{2}$ solution at room temperature. Each dip lasted about 15 to $30 \mathrm{~s}$ and was followed by washing, using slowly immersion in distilled water for about $15 \mathrm{~s}$ between each dip.

After nucleation, the substrate showed a very light brown color and the tape was removed. After activation step, an accelerating operation was performed by dipping the substrate in a $10 \% \mathrm{NaOH} .{ }^{29}$ This solution gave the finest remaining particles, which were almost bare active nuclei. ${ }^{20}$

\section{Electroless}

Electroless $\mathrm{Cu}$ deposition can be described by two reactions, which occur simultaneously on a catalytic surface, including oxidation reaction of a reducing agent and reducing reaction of $\mathrm{Cu}$ ions. ${ }^{41}$

The flow of electrons required for the oxidationreduction reaction is provide by the species present in the solution. ${ }^{10}$ The overall reaction of electroless $\mathrm{Cu}$ deposition can be described by the equation $2 .^{22,42,43}$

$$
\begin{aligned}
& \mathrm{Cu}^{2+}+2 \mathrm{HCHO}+4 \mathrm{OH}^{-} \rightarrow \mathrm{Cu}^{0}+\mathrm{H}_{2} \uparrow+2 \mathrm{H}_{2} \mathrm{O}+ \\
& 2 \mathrm{HCOO}^{-}
\end{aligned}
$$

After surface treatment, a non-commercial autocatalytic solution of electroless $\mathrm{Cu}$, similar to that reported by Iacovangelo ${ }^{44}$ and Baumgartner, ${ }^{45}$ was used (Table 2).

The deposition was performed at $30 \pm 1^{\circ} \mathrm{C}, \mathrm{pH}$ adjusted using $\mathrm{NaOH}$ to a final value of 12.5 and with stirrer agitation. Under these conditions, the deposition rate is $50 \mathrm{~nm} \mathrm{~min}{ }^{-1}$. Finally, the substrate was rinsed with DI water and dried using gas nitrogen $\left(\mathrm{N}_{2}\right)$. Stabilizer and buffer were also added to the plating bath to increase the bath stability and to decrease the surface tension of the solution.

Figure 1 shows the scheme of electroless deposition of $\mathrm{Cu}$ onto alumina particles using the surface treatment and ED processes.

\section{Characterization}

Surface wettability of the alumina before and after

Table 1. Composition of sensitization and activation solution

\begin{tabular}{lcccc}
\hline & Sensitization solution & & Activation solution \\
\cline { 1 - 2 } $\mathrm{SnCl}_{2}$ (ACS, Merck, Darmstadt, Germany) & Concentration & Component \\
$\mathrm{HCl}(37 \%$ ACS-ISO, Merck, Darmstadt, Germany) & $2 \mathrm{~mL}$ & & $\mathrm{PdCl}_{2}$ (ACS, Merck, Darmstadt, Germany) \\
\hline
\end{tabular}

Table 2. Cu bath composition

\begin{tabular}{lcc}
\hline Compound & Function & Concentration / ( $\left.\mathrm{L} \mathrm{L}^{-1}\right)$ \\
\hline $\mathrm{CuSO}_{4} \cdot 5 \mathrm{H}_{2} \mathrm{O}$ (PA-ACS, Synth, Diadema, Brazil) & ion source & 8.0 \\
$\mathrm{NaKC}_{4} \mathrm{H}_{4} \mathrm{O}_{6} \cdot 4 \mathrm{H}_{2} \mathrm{O}$ (PA-ACS, Synth, Diadema, Brazil) & complexing agent & 32 \\
$\mathrm{HCHO}(37 \%$ PA, Synth, Diadema, Brazil) & reducing agent & $12 \mathrm{~mL}$ \\
$\mathrm{NaHCO}_{3}$ (ACS, Synth, Diadema, Brazil) & buffer & 10 \\
$\mathrm{KCN}(\mathrm{PA}$, Merck, Darmstadt, Germany) & stabilizer & 0.02 \\
\hline
\end{tabular}




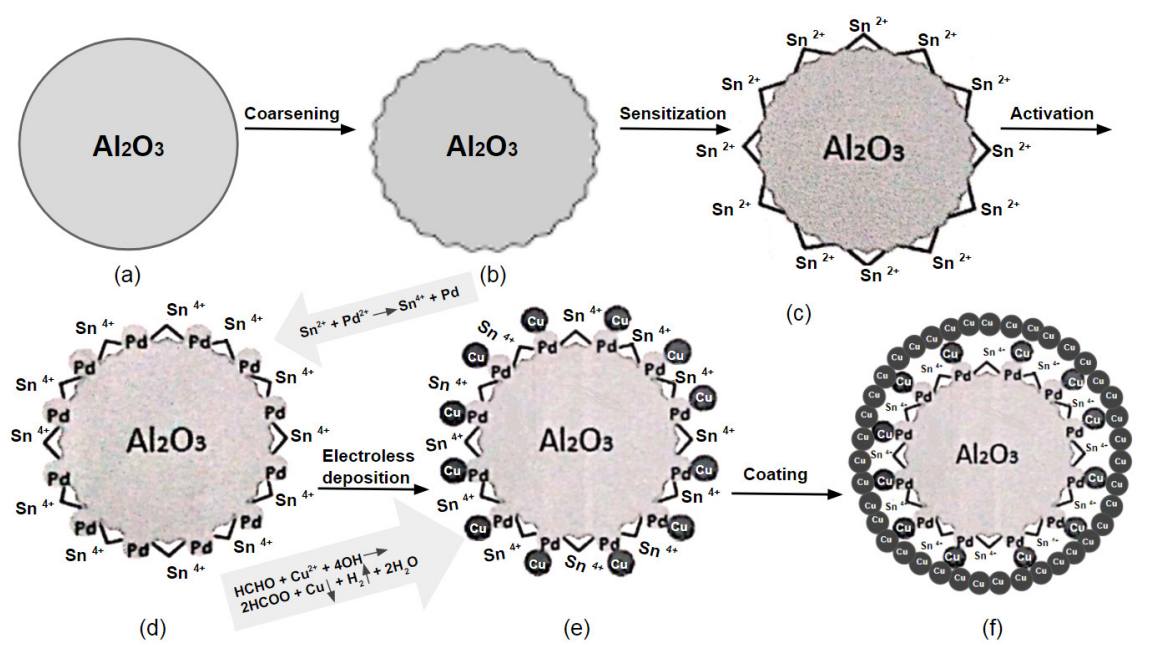

Figure 1. Schematic of $\mathrm{Cu}$ deposition on the surface alumina particles (adapted from reference 22).

coarsening was evaluated by a contact angle system model OCA 15 plus (Dataphysics Instruments GmbH, Filderstadt, Germany).

Atomic force microscopy (AFM) (Nanosurf FlexAFM model C3000, Liestal, Switzerland), scanning electron microscopy (SEM-FEG) model Mira 3 x MU from TESCAN (Brno, Czech Republic) used at $5 \mathrm{kV}$, SEM coupled with Bruker Quantax System energy dispersive spectroscopy (EDS) and profilometer DekTak XT (Bruker, Billerica, USA, scan $500 \mu \mathrm{m}$, velocity of $30 \mathrm{~s}$ ) were used to characterize the $\mathrm{Cu}$ thin film.

\section{Results and Discussion}

\section{Surface treatment}

Seeds for deposition are necessary in the electroless plating of insulator. There are no metallic bonds between the ceramics and copper coating, but unstable mechanical combination. So, coarsening is carried out to increase the micro roughness of the surface and to obtain a hydrophilic substrate in order to acquire good adhesive coatings on the substrate. ${ }^{46}$

To have a qualitative assessment of whether there was a change in the behavior on the $\mathrm{Al}_{2} \mathrm{O}_{3}$ surface after coarsening, surface wettability was evaluated by a contact angle. Figure 2a showed that the surface of the polished alumina prior to the treatment was very hydrophobic, so the drop of water practically did not spread on the polished alumina surface, unlike the treated alumina surface (Figure 2b) which was quite hydrophilic and where the drop greatly spreads.

This behavior indicates that there was a morphological change on the alumina surface. This change was confirmed by the scanning electron microscopy (Figure 3 ).

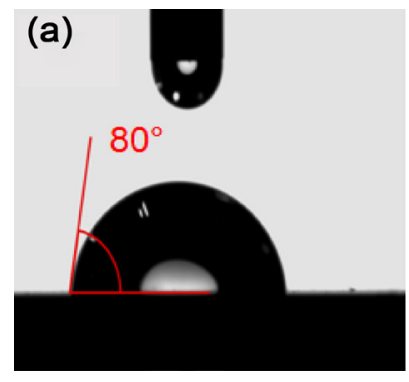

(b)

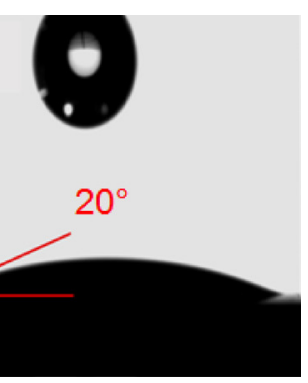

Figure 2. Contact angle images of (a) before treatment, (b) after treatment.
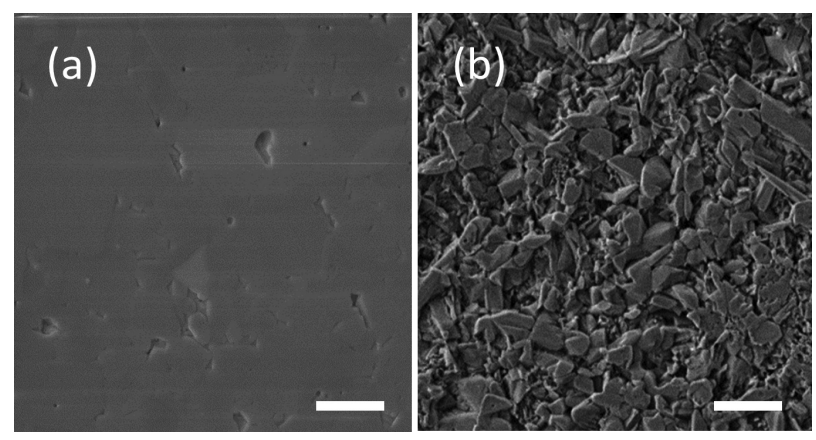

Figure 3. SEM images of polished alumina (a) before treatment and (b) after coarsening. Scale bar $2 \mu \mathrm{m}$.

Figure 3 shows the surface morphology of the untreated and pretreated polished alumina. The untreated alumina (Figure 3a) comprises uniform, fused $\mathrm{Al}_{2} \mathrm{O}_{3}$ particles with small defects near to $1 \mu \mathrm{m}$, which are probably due to the polishing performed in its production. Figure $3 b$ shows the change that occurred after acid-basic coarsening, indicating an increase in roughness. According to Honma and Kanemitsu, ${ }^{24}$ the glass phase of the alumina surface was dissolved by coarsening and polar groups were formed (equation 3):

$\mathrm{Si}-\mathrm{O}^{-} \mathrm{Na}+\mathrm{H}^{+} \rightarrow \mathrm{Si}-\mathrm{OH}+\mathrm{Na}^{+}$ 
Thus, absorption of the catalyst increases the adhesion strength of metals using ED deposition processes.

Figure 4 shows the roughness measured by a profilometer DekTak XT in two points of the sample (P1 and P2). It is verified that the roughness before treatment (black and green lines) is about $25 \mathrm{~nm}$ on the polished alumina surface $(99.9 \%)$. The roughness of the $\mathrm{Al}_{2} \mathrm{O}_{3}$ surface after the treatment (blue and red lines) is in the order of $50 \mathrm{~nm}$. The roughness increase measured on the scan profile confirms the coarsening observed on SEM images on Figure 3 and proposed by Beygi et al. ${ }^{22}$ (Figure 1). This increase in roughness $(25 \mathrm{~nm})$ is already enough to obtain a catalytic surface with the possibility of adhesion of the $\mathrm{Cu}$ to be deposited by the ED process.

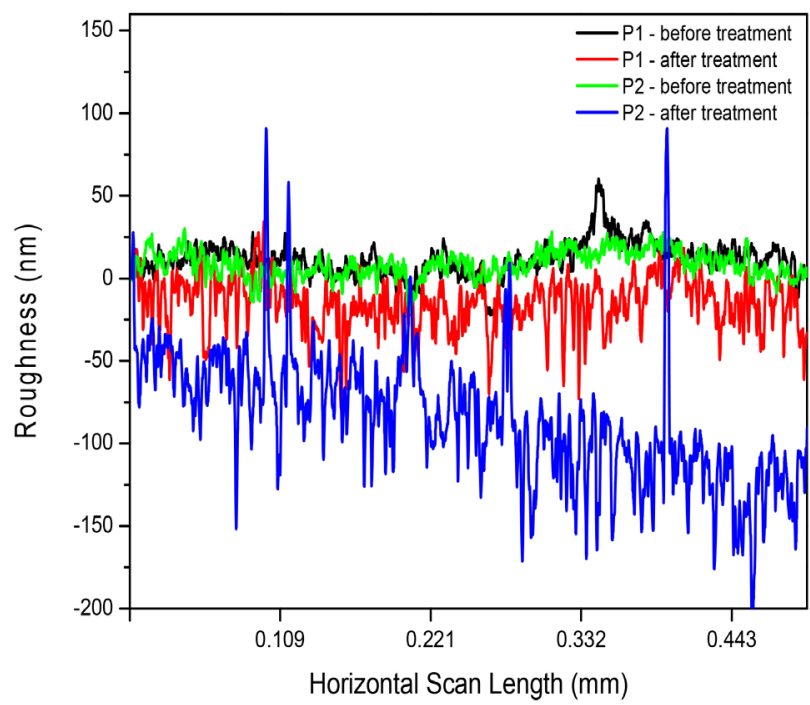

Figure 4. Roughness of untreated and treated polished alumina; P1 and $\mathrm{P} 2$ are two different areas on the same sample.

\section{Electroless copper deposition}

Electroless deposition of $\mathrm{Cu}$ is very popular in printed circuit board (PCB) manufacturing and $\mathrm{Cu}$ plating application for features with critical dimensions in the range of $10 \mu \mathrm{m} .{ }^{47}$ Moreover, this process offer several features such as (i) high selectivity; (ii) uniform thickness, particularly for objects with complex geometry; (iii) uniform physical and mechanical properties; (iv) high rate of deposition by tuning the solution composition, $\mathrm{pH}$ and temperature for commercial applications; $(v)$ deposition on non-conducting surface, and ( $v i)$ very economic cost of tools and materials. ${ }^{48}$

To understand this process in detail, a few fundamental ideas need to be reviewed. Generally, for any electrochemical deposition process, coating bath plays a key role. In the case of ED, the coating bath consist of metal ions, a reducing agent, a complexing agent, a stabilizer and additives. ${ }^{49}$
The electromechanism of electroless plating is explained by two half reactions: an oxidation half reaction (anodic oxidation of the reducing agent) and a reduction half reaction (cathodic reduction of the metal ions).$^{50}$ These half reactions are characterized by redox oxidation or reductions reactions electrode potentials. The redox electrode potential related to the Gibbs free energy $(\Delta \mathrm{G})$ and the rate constant of the electrode $(\mathrm{K})$ and these parameters are used to predict the electrochemical reaction tendency. ${ }^{51}$ The catalytic activity of the $\mathrm{Cu}$ ion promoting oxidation of the reducing agent determines the reduction phenomenon of $\mathrm{Cu}$ on the substrate. The ligands developed from chemical reactions can act as accelerators for the deposition process. These complexes facilitate decreasing the reduction potential difference with reducing agents. ${ }^{52}$

Figures $5 \mathrm{a}$ and $5 \mathrm{~b}$, employed by SEM, showed homogeneous coating over the alumina substrate area with submicron particles of $\mathrm{Cu}$ deposited on a smooth rough surface forming a thin nanostructured film.

It can be said that one of the attributions for the $\mathrm{Cu}$ film to remain with low roughness and smaller particles is due to the temperature of the solution $\left(30^{\circ} \mathrm{C}\right)$ during the ED deposition of the $\mathrm{Cu}$ film.

The uniformity of the $\mathrm{Cu}$ film deposition can be better evaluated in Figure 5a, since the analyzed area is $10 \mu \mathrm{m}$, while in Figure 5b, the absence of holes and cracks is better observed because the analyzed area is ten times smaller.
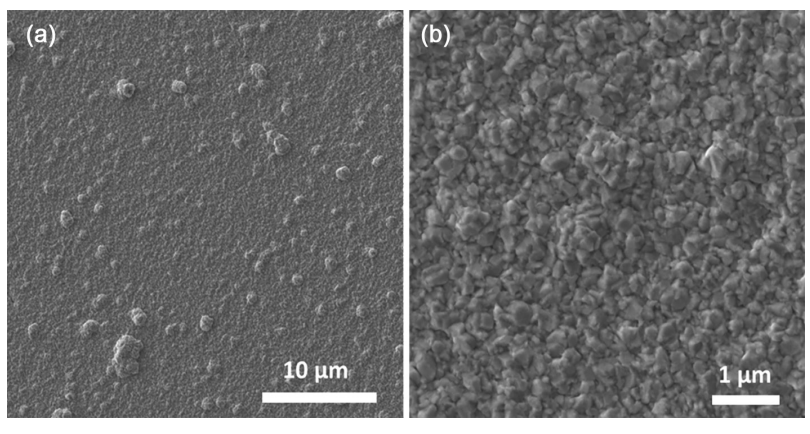

Figure 5. SEM images $2 \mathrm{D}$ of $\mathrm{Cu}$ morphology thin film plating $\mathrm{Al}_{2} \mathrm{O}_{3}$. Scale: (a) $10 \mu \mathrm{m}$ and (b) $1 \mu \mathrm{m}$.

Figure 6 a shows the image obtained by AFM of $\mathrm{Cu}$ thin film plating $\mathrm{Al}_{2} \mathrm{O}_{3}$ containing four-profile lines (Figure 6b) obtained through analysis by Gwyddion v 2.27 software. ${ }^{53}$ The line profile analysis showed an average cluster size of approximately $1 \mu \mathrm{m}$. Furthermore, the average roughness (Ra) of $40 \mathrm{~nm}$ was also obtained over $10 \times 10 \mu \mathrm{m}$ area (Figure 6a).

Figure 7 a shows the analysis obtained by energy dispersive spectroscopy (EDS) coupled with SEM for elemental mapping of $\mathrm{Cu}$ thin film plated (Figure $7 \mathrm{~b}$ ). 


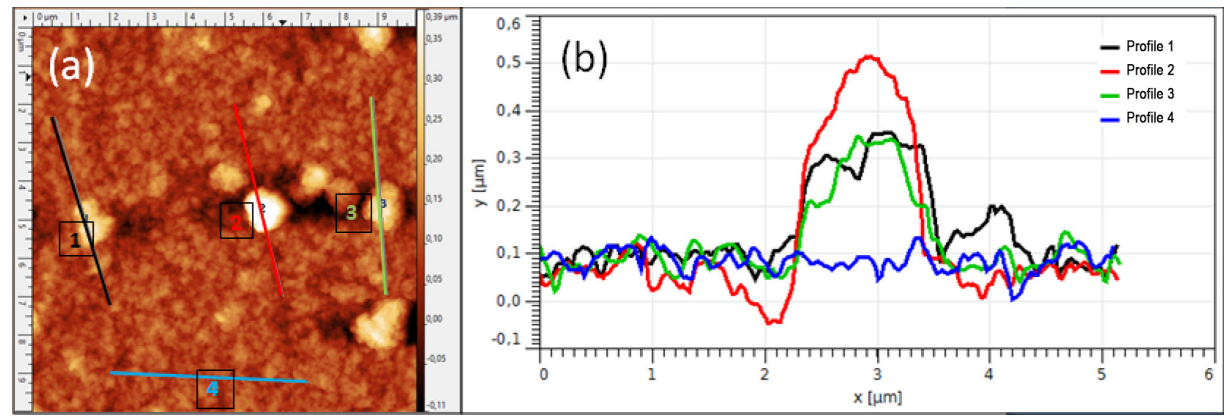

Figure 6. (a) AFM image of $\mathrm{Cu}$ plating $\mathrm{Al}_{2} \mathrm{O}_{3}$. (b) Line profile graphic showing the surface roughness over four different scans. Analysis obtained by Gwyddion free software. ${ }^{33}$

Through this analysis we observed the high purity (greater than $87 \%$ ) of $\mathrm{Cu}$ thin film after the surface $\mathrm{Al}_{2} \mathrm{O}_{3}$ treatment. In addition, the percentages of $\mathrm{Al}$ and $\mathrm{O}$ come from the residual reading. On the other way, the percentage of $\mathrm{C}$ present in the $\mathrm{Cu}$ film (greater than 7\%) suggested that during the electrochemical deposition, the chemical reducing agent $(\mathrm{HCHO})$ released $\mathrm{C}$ that were incorporated into the $\mathrm{Cu}$ plated. As formaldehyde acts directly in the oxi-reduction reaction of copper, it is probably the source of carbon. Natividad et al. ${ }^{10}$ performed X-ray photoelectron spectroscopy (XPS) analyses and suggested the presence of $\mathrm{Pd}-\mathrm{Cu}$ alloys after the whole plating $\mathrm{Cu}$ process. However, $\mathrm{Pd}$ is harder to detect by EDS analyses in relation to the other elements.

Figure 8 shows the 3D surface roughness of alumina after coarsening and the $\mathrm{Cu}$ thin film deposited analyzed by atomic force microscopy (AFM). Figure 8a showed the top-view image of polished alumina after coarsening in a $5 \times 5 \mu \mathrm{m}$ area and Figure $8 \mathrm{~b}$ after electroless $\mathrm{Cu}$ deposition in a $10 \times 10 \mu \mathrm{m}$ area. Figure $8 \mathrm{~b}$ shows that de $\mathrm{Cu}$ coating is homogeneous and uniform. Figure $8 \mathrm{c}$ was taken in an area $2 \times 2 \mu \mathrm{m}$ and shows the absence of cracks and flaws after the $\mathrm{Cu}$ plating. The roughness observed on the $\mathrm{Al}_{2} \mathrm{O}_{3}$ surface after coated with $\mathrm{Cu}$ comes from coarsening. The AFM images of alumina after coarsening and electroless $\mathrm{Cu}$ deposited on the alumina at $30^{\circ} \mathrm{C}$, alkaline $\mathrm{pH}$ and using $\mathrm{HCHO}$ as reducing agent, complement and confirm the results obtained by SEM-FEG and DekTak-XT equipment's.

\section{Conclusions}

In this work, we proposed a surface treatment as lowcost alternative to other more expensive methods, such as chemical vapor deposition (CVD), physical vapor deposition (PVD), plasma spraying or electrodeposition, to obtain a good adherence with metallic film. The four stages treatment process permitted the development of a fully wet $\mathrm{Cu}$ deposition process and shows a good alternative to obtain a $\mathrm{Cu}$ thin film with low processing cost. The different stages of pretreatment and electroless deposition of $\mathrm{Cu}$ on polycrystalline alumina have been studied by means of SEM, EDS, AFM and DekTak XT equipment's and observed high uniformity, absence of holes, cracks and reduced surface roughness in alumina sample coated whit $\mathrm{Cu}$ film.
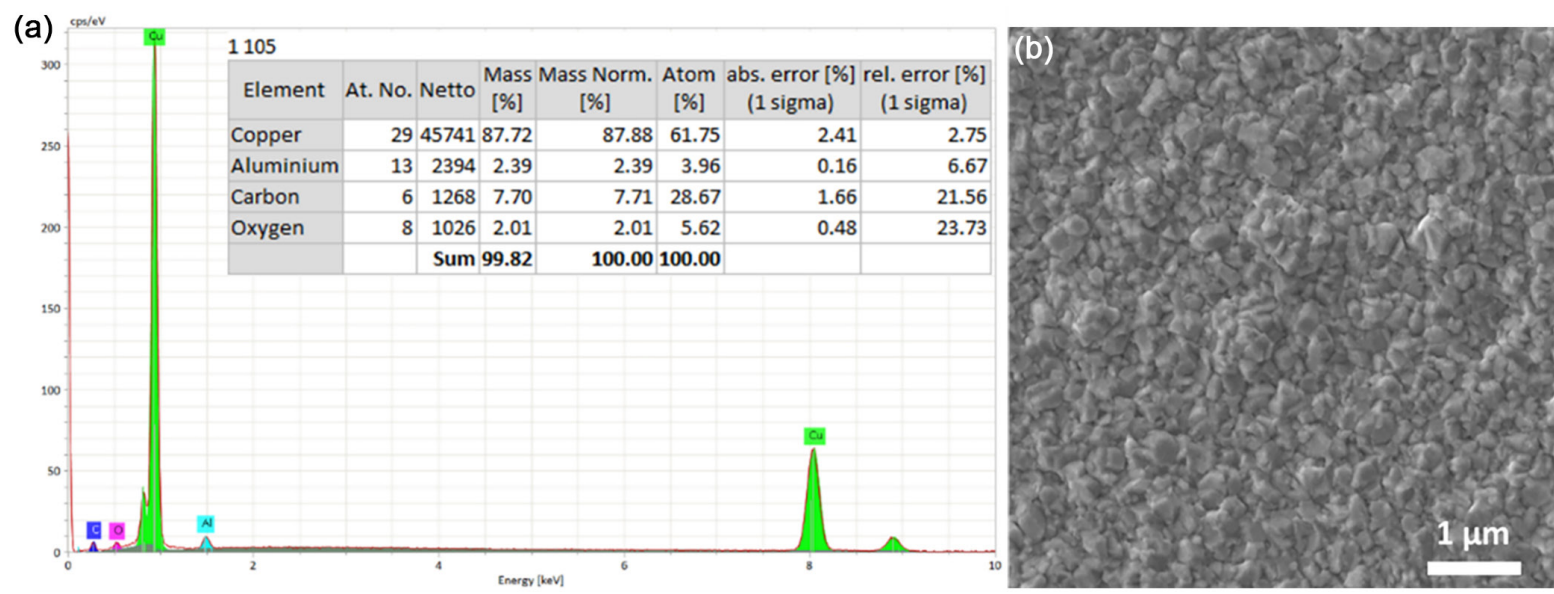

Figure 7. EDS elemental spectrum and quantification results of electroless $\mathrm{Cu}$ deposition over $\mathrm{Al}_{2} \mathrm{O}_{3}$ substrate (a), obtained by $\mathrm{SEM}$ image $2 \mathrm{D}$ of $\mathrm{Cu}$ morphology (b). 

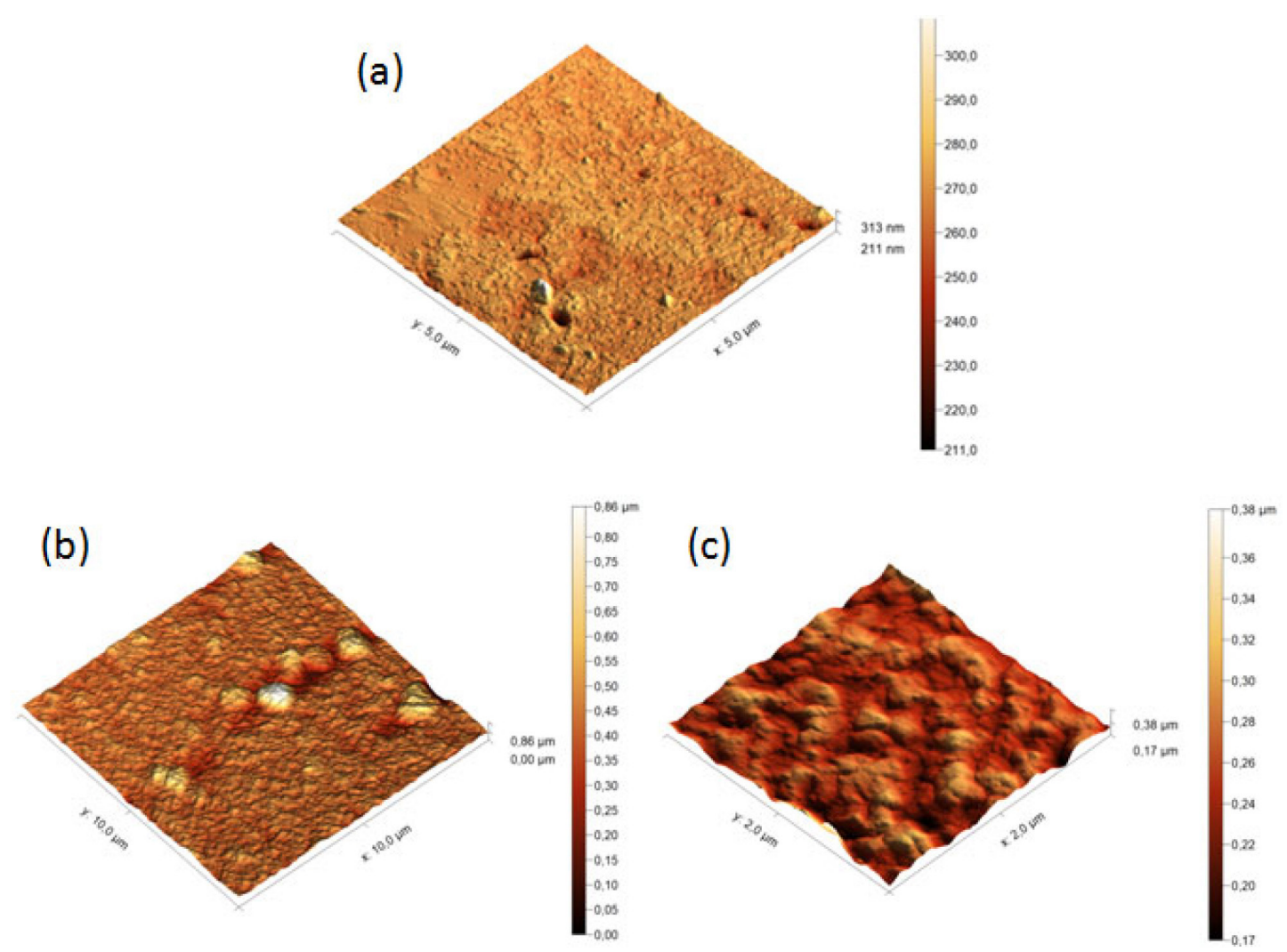

Figure 8. Images of 3D surface roughness of (a) alumina after coarsening in $5 \times 5 \mu \mathrm{m}$ area; (b) and (c) after Cu ED in a $10 \times 10$ and $2 \times 2 \mu \mathrm{m}$ area, respectively.

The surface treatment also showed a high performance in the $\mathrm{Cu} \mathrm{ED}$ film at low temperature $\left(30^{\circ} \mathrm{C}\right)$, obtaining more compact and uniform film, with small grain size and a high purity $\mathrm{Cu}$ metallic deposit. From the results obtained in this study, we can conclude that the sequence of metallization of high purity and polished $\mathrm{Al}_{2} \mathrm{O}_{3}$ substrate (99.9\%) was established, based on autocatalytic (electroless) techniques of film deposition.

\section{Acknowledgments}

The authors thank the Assembly, Packaging and System Integration Division (DIMES) and Renato Archer Center for Information Technology (CTI), by the opportunity to use the facilities and equipment. The authors also thank the National Council for Scientific and Technological Development (CNPq) for financial support. The authors are especially grateful to Cristina B. Adamo for her valuable contribution towards the development regarding the treatment of ceramic surfaces between years 2012-2016.

\section{References}

1. Kobayashi, T.; Ishibashi, J.; Mononobe, S.; Ohtsu, M.; Honma, H.; J. Electrochem. Soc. 2000, 147, 1046.
2. Ting, C. H.; Paunovic, M.; Pai, P. L.; Chiu, G.; J. Electrochem. Soc. 1989, 136, 462.

3. Khoperia, T. N.; Tabatadze, T. J.; Zedginidze, T. I.; Electrochim. Acta 1997, 42, 3049.

4. Watanabe, W.; Honma, H.; J. Electrochem. Soc. 1977, 144, 471.

5. Khoperia, T. N.; Zedginidze, T. I.; ECS Trans. 2008, 11, 87.

6. Honma, H.; Koshio, T.; Hotta, S.; Watanabe, H.; Plat. Surf. Finish. 1995, 127, 60.

7. Hsu, H.-H.; Lin, K.-H.; Lin, S.-J.; Yeh, J.-W.; J. Electrochem. Soc. 2001, 148, C47.

8. Li, J.; O'Keefe, M. J.; O'Keefe, T. J.; Surf. Coat. Technol. 2011, $205,3134$.

9. Schlesinger, M. In Electroless Deposition on Nickel, Modern Electroplating, $5^{\text {th }}$ ed.; Schlesinger, M.; Paunovic, M., eds.; John Wiley \& Sons: Hoboken, New Jersey, 2010, ch. 18, p. 447.

10. Natividad, E.; Lataste, E.; Lahaye, M.; Heintz, J. M.; Silvain, J. F.; Surf. Sci. 2004, 557, 129.

11. Lu, Z. L.; Wang, Z. C.; Luo, L. M.; Huang, M. X.; Tan, Y. X.; Chen, B. J.; Cheng, G. J.; Wu, C. Y.; Surf. Eng. 2015, 31, 240.

12. Uysal, M.; Karslioglu, R.; Alp, A.; Akbulut, H.; Ceram. Int. 2013, 39, 5485.

13. Karthikeyan, S.; Jeeva, A. P.; Narayanan, S.; Srinivasan, N. K.; $\mathrm{Hu}$, X.; Surf. Eng. 2012, 28, 743.

14. Guo, H. R.; Jiang, K. S.; Yuen, W. M. C.; Ng, F. C. M.; Surf. Eng. 2009, 25, 101. 
15. Osaka, T.; Koiwa, I. T.; Svendsen, G. L.; J. Electrochem. Soc. 1985, 132, 2081.

16. Honma, T.; Naito, K.; Takai, M.; Osaka, T.; Yamazaki, Y.; Namikawa, T.; J. Electrochem. Soc. 1991, 138, 1269.

17. Zhang, C. M.; Kang, T. E.; Neoh, G. K.; Tan, L. K.; J. Electrochem. Soc. 2001, 148, C71.

18. Honma, T.; Yamaguchi, R.; Murao, Y.; J. Electrochem. Soc. 1993, 140, 687.

19. Yamagishi, K.; Okamoto, N.; Mitsumata, M.; Fukumuro, N.; Yae, S.; Matsuma, H.; J. Electrochem. Soc. 2004, 82, 114.

20. Osaka, T.; Nagasaka, H.; Goto, F.; J. Electrochem. Soc. 1980, $127,2343$.

21. O’Sullivam, M. J. E.; Horkans, J.; White, R. J.; Roland, M. J.; IBM J. Res. Dev. 1988, 32, 591.

22. Beygi, H.; Sajjadi, A. S.; Zebarjad, M. S.; Appl. Surf. Sci. 2012, $261,166$.

23. Svendsen, G. L.; Osaka, T.; Sawai, H.; J. Electrochem. Soc. 1983, 130, 2252.

24. Honma, H.; Kanemitsu, K.; Plat. Surf. Finish. 1987, 74, 62.

25. Honma, H.; Kouchi, Y.; J. Electrochem. Soc. 1990, 75, 54.

26. Grunwald, J. J.; Gottesfeld, S.; Laser, D. G.; Plat. Surf. Finish. 1981, 68, 10.

27. Horkans, J.; Kim, J.; McGrath, C.; Romankiw, T. L.; J. Electrochem. Soc. 1987, 134, 300.

28. Lung, K.; Jong, S.-C.; Mater. Chem. Phys. 1993, 35, 53.

29. Chikouche, I.; Sahari, A.; Zouaoui, A.; Zegadi, A.; Surf. Rev. Lett. 2016, 23, 1550086.

30. Zang, Z.; Appl. Phys. Lett. 2018, 112, 042106.

31. Cui, X.; Hutt, D. A.; Conway, P. P.; Thin Solid Films 2012, 520 , 6095.

32. CoorsTek; Thin-Film Ceramic Substrates Design Guide; 2011, available at https://www.coorstek.com/media/4222/thin-filmceramic-substrates-design-guide.pdf, accessed in January 2022.

33. Honma, H.; Kouchi, Y.; Plat. Surf. Finish. 1990, 35, 54.

34. Browning, M. E. In Surface Engineering, ASM Handbook, vol. 5; Cotell, C. M.; Sprague, J. A.; Smidt Jr., F. A. eds.; ASM: Geauga County, Ohio, USA, 1990, p. 308.
35. van der Putten, M. T. A.; de Bakker, J.; Fakkink, J. G. L.; J. Electrochem. Soc. 1992, 139, 3475.

36. Ilias, S.; Su, N.; Udo-Aka, I. U.; King, F. G.; Sep. Sci. Technol. 1997, 32, 487.

37. Gan, X.; Zhou, K.; Hu, W.; Zhang, D.; Surf. Coat. Technol. 2012, 206, 3405.

38. Campos, M. D. C.; Flacker, A.; Vaz, R. A.; Moshkalev, A. S.; Nobrega, O. G. E.; J. Electrochem. Soc. 2011, 158, D330.

39. Volpe, M.; Inguanta, R.; Piazza, S.; Sunseri, C.; Surf. Coat. Technol. 2006, 200, 5800.

40. Ozaki, T.; Zhang, Y.; Komaki, M.; Nishimura, C.; Int. J. Hydrogen Energy 2003, 28, 297.

41. Dubin, M. V.; Diamand, S. Y.; Zhao, B.; Vasudev, K. P.; Ting, H. C.; J. Electrochem. Soc. 1997, 144, 898.

42. Matsuoka, M.; Murai, J.; Iwakura, C.; J. Electrochem. Soc. 1992, 139, 2466.

43. Dehchar, C.; Chikoouche, I.; Kherrat, R.; Sahari, A.; Zouaoui, A.; Merati, M.; Mater. Lett. 2018, 228, 439.

44. Iacovangelo, D. C.; J. Electochem. Soc. 1986, 133, 1359.

45. Baumgartner, E. C.; Plat. Surf. Finish. 1989, 61, 53.

46. Ma, H.; Liu, Z.; Wu, L.; Wang, Y.; Wang, X.; Thin Solid Films 2011, 519, 7860 .

47. Diamand, S. Y.; Dubin, M. V.; Angyal, M.; Thin Solid Films 1995, 262, 93.

48. Sudagar, J.; Lian, J.; Sha, W.; J. Alloys Compd. 2013, 571, 183.

49. Ge, J.; Turunen, M. P. K.; Kivilahti, J. K.; J. Polym. Sci., Part B: Polym. Phys. 2003, 41, 623.

50. Paunovic, M.; Plating 1968, 55, 1161.

51. Oldhan, K. B.; Mayland, J. C.; Fundamentals of Electrochemical Science; Academic Press: New York, 1994.

52. Ghosh, S.; Thin Solid Films 2019, 669, 641.

53. Gwyddion, version 2.27; Department of Nanometrology, Czech Metrology Institute, Brno, Czech Republic, 2018, available at http://gwyddion.net/, accessed in January 2022.

Submitted: November 1, 2021 Published online: January 25, 2022 